\title{
FOREIGN EXCHANGE EXPECTATIONS IN INDONESIA: REGIME SWITCHING CHARTISTS \& FUNDAMENTALISTS APPROACH
}

\author{
Ferry Syarifuddin \\ Noer Azam Achsani \\ Dedi Budiman Hakim \\ Toni Bakhtiar
}

\begin{abstract}
In this research, the effect of central bank intervention within a heterogeneous expectation exchange rate model is investigated. The results are supporting both chartists and fundamentalist regimes. In the period investigated, chartist dominates in determining the exchange rate. While BI foreign exchange intervention can effectively push the market exchange-rate to its long-run fundamental equilibrium, however, Bank Indonesia's effort to exert a stabilizing effect of foreign exchange interventions, the result does not show a success.
\end{abstract}

Keywords: exchange rates, foreign-exchange intervention, switching regression JEL Classification: F31, E52, C24

\footnotetext{
Post-graduate student, Bogor Agricultural University, Graduate Program of Business \& Management, ferry.s@bi.go.id. Lecturer, Bogor Agricultural University, Graduate Program of Business \& Management, achsani@yahoo.com. Lecturer, Bogor Agricultural University, Graduate Program of Business \& Management, dbhakim@bima.ipb.ac.id.

4 Lecturer, Bogor Agricultural University, Graduate Program of Business \& Management, tonibakhtiar@yahoo.com.
} 


\section{INTRODUCTION}

According with the postulate impossible trinity, freely floating exchange rate will be adapted by a country which adapts freely foreign exchange system and independent monetary policy. Indonesia is one of country that adapts it. By freely floating exchange rate and position as a small open economy, Indonesia's exchange rate movement is strongly influenced by capital flows moreover in the short run. In foreign exchange market, capital flows is a reaction of foreignexchange players to buy or sell foreign exchange. Foreign-exchange player can be categorized in two groups. First group called fundamentalists, buy or sell foreign exchange based on their expectation of future exchange rate with regard to fundamental economic condition. The other group called chartist, buy or sell foreign exchange based on their expectation on future exchange rate with regard to previous exchange-rate behavior. These two groups determine market exchange-rate as reflected by interaction of supply and demand of foreign exchange. Sometimes, the exchange rate moves beyond their fundamental value. Hence, existence of central bank's. Foreign-exchange intervention policy is needed to drive the exchange rate back to its long-run fundamental value. The main results in the empirical literature (Almekinders and Sylvester, 1996; Frenkel, 2004; Ito and Yabu, 2007; and in papers of surveys Neely and Weller, 2001) suggest that foreign-exchange intervention policy tend to be conducted in order to reduce exchange rate misalignment or to reduce foreign exchange undesired fluctuations.

Foreign-exchange interventions by the central bank could be categorized in two parts. Firstly, a foreign-exchange intervention (non-sterilized) occurs when a monetary authority buys (sells) foreign exchange which affect the monetary base, interest rates, market expectations and intimately the exchange rate. Secondly, foreign-exchange intervention is said sterilized if the monetary authority offsets or sterilizes the effect of the foreign exchange operation on the monetary base by selling or buying domestic bonds in order to keep the monetary policy unchanged.

With the central bank policy, the exchange rates would hopefully stay in the desired level and its stability can be ensured. Nevertheless, beside relying on central bank policy to stabilize the exchange rate, financial agents are sometimes actively hedging the exchange rate in order to avoid losses due to exchange rate fluctuations. Röthig, Semmler, and Flaschel (2005) argued that the negative effect of exchange rate on the balance sheet can be eliminated by risk management like hedging. Hedging generally conducts by forward transactions, swaps, NDF etc.

In this part of paper, the behavior of microstructure of foreign exchange market players (fundamentalists and chartists) in determining exchange rate is investigated. This approach is hopefully able to overcome the failure of numerous empirical studies based on the asset market approach of exchange rate to explain short term movements of exchange rate (Lewis, 1995 and Taylor, 1995. This paper adopts the exchange-rate microstructure approach called 'noise trading' channel pioneered by Hung (1997) and the coordination channel Reitz and Taylor (2008), and Taylor (2004), (2005). Ahrens and Reitz (2003) perform empirical study regarding 
to this issue and their result provide evidence that the heterogeneous expectations exchange rate model is able to explain daily German-US forward rates. Further research by Maatoug, Fatnassi, Omri (2010) finds that both regimes (fundamentalists and chartists) are persistent in Australia. However he finds that the fundamentalists regime is riskier and when the RBA was not active in the foreign exchange, the fundamentalists were disappeared. Other study using marcov switching approach by Brunetti, Mariano, Scotti (2007) in Southeast Asia, finds that real effective exchange rates, money supply, stock index returns, are important variables to identify turbulence and ordinary periods.

To investigate different forecasting strategies by the players, the impact of central bank intervention is investigated applying a heterogeneous expectations exchange rate model. The approach is also evaluated by including central bank intervention policy to drive exchange rate to its long-run fundamental value. Foreign-exchange interventions would allow foreignexchange intervention to influence the both forecasting rules of chartists and fundamentalists, thereby altering the proportion of the two groups in the foreign exchange market. A central bank intervening in the foreign exchange market is considered effective if the exchange rate is driving closer to its fundamental value. Generally, foreign-exchange intervention may as well improve the performance of expectations based on fundamentals, especially when central banks try to correct current exchange rate misalignments. Following Frankel and Froot (1986) the excess demand/supply for foreign currency is assumed to be a function of the relative success of chartist and fundamentalist forecasting techniques. At the end, it is suggested that the performance of chartist or fundamentalist exchange-rate expectation is expected to be improved by central bank intervention.

This research furthermore re-examines the effects of foreign-exchange intervention on exchange rate volatility within the heterogeneous groups in the foreign exchange market. These studies suggested two new channels through which sterilized intervention may be transmitted: the noise trading channel (Hung, 1997) assuming two hypotheses: noise traders will determine exchange rate by flow market equilibrium and the central bank should intervene in highly volatile market periods and keep its interventions secret (Reitz, 2002).

The remainder of the paper is organized as follow. Section 2 describes the theory and literature study, followed by Research Methodology in section3. Our main empirical results concerning intervention effectiveness are reported in section 4, before the final section (5) concludes.

\section{THEORY}

\subsection{Foreign Exchange Market Microstructure}

In macro perspective, foreign exchange level should reflect the fundamental economy condition. As described so far, the determinants of the exchange rate like inflation, productivity, interest rate, etc categorized as fundamental factors which significantly affect long-run exchange- 
rate. Furthermore, news related to the fundamental factors such as statistic announcements of money supplies, trade balances, or fiscal policies is received by the market, and the exchange rates will also change to reflect this news. However, there is also significant issue regarding foreign-exchange microstructure which also determine exchange rates. Understanding the "market microstructure" allows us to explain the evolution of the foreign exchange rate, in which foreign exchange traders adjust their foreign-exchange purchase or sale based on their own rules. In addition to macroeconomic indicators news, there also exists private information from which some traders know more than others about the current state of the market.

As illustrated in Figure 1, exchange rate is determined by two groups according to different approaches of expectations; the fundamental analysis and the chartist analysis. The classification was proposed previously by Frankel and Froot $(1986,1990)$, and has been enhanced among others by Ahrens and Reitz (2003), Reitz (2002), Westerhoff (2003), Wieland and Westerhoff (2005). In this diagram, the market exchange-rate is built by combining fundamentalists and chartists exchange-rate expectation adjusted by their own proportion in the foreign-exchange market. In the period of misaligned exchange-rate from desired value, central bank will enter the market to re-adjust the exchange rate to its desired level or mitigate the short-term fluctuations.

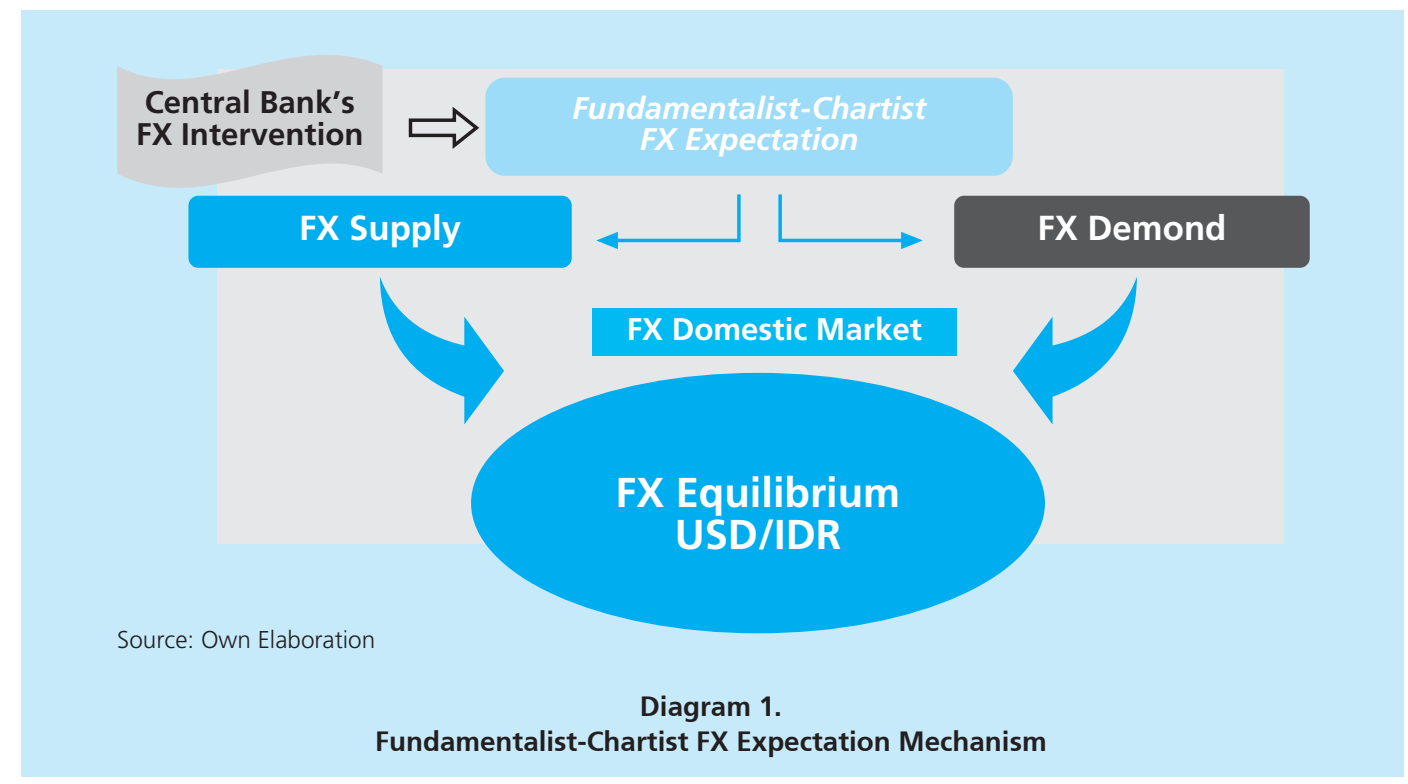

\subsection{Monetary and Exchange Rate Policies}

Global financial market has been pushing emerging countries financial market also more integrated to the global financial market. As return of assets offered is often higher than ones 
in advanced financial market, the asset return including exchange rate is moving with more fluctuates. This condition is not accepted by most central banks as it will ignite more uncertainty in their financial market. There are some reasons behind that such as, first, large movements in the real exchange rate away from medium-run equilibrium are costly, and second, there is imperfect capital mobility/asset substitutability. To overcome this phenomenon, most central banks in emerging market economies implement various monetary policies. The most popular ones are sterilized intervention and short-term policy rate. This opens up the fortuitous possibility that policy makers may be operating in a two-target, two-instrument world. In this note, this research re-examines the case for using two policy instruments (the policy interest rate and FX market intervention) under an IT regime in Indonesia's financial market. Hence, a central bank indeed implements two instruments (the policy interest rate and FX intervention).

Lesson learned from previous financial crises, push central banks to maintain stable consumer prices if they are to achieve sustained and stable growth. Therefore, the central banks need more policies than just the policy interest rate such as foreign-exchange interventions. Lesson learned from previous financial crises, central banks should maintain stable consumer prices as well as promote sustainable growth in order to avoid the financial crises. Therefore, the central banks need more policies than just the policy interest rate such as foreign-exchange interventions. One more important think is the central bank should also maintain financial sector stability including stable exchange-rate and healthy domestic financial institutions in micro perspective. Regarding to exchange rate, the central bank should avoid possible large deviations of the exchange rate from its medium-run equilibrium, even in an inflation target which requires floating exchange-rate system. The undesired exchange rate fluctuations might be response shortly by foreign-exchange intervention, if it moves persistently. Response to such changes can deliver better economic outcomes under ITF which requires free-floating exchange-rate system (but in some reason, a measured foreign-exchange intervention to drive the exchange rate in line with desired inflation, cannot be neglected) than being neglect of the exchange rate (Stone, Roger, Shimizu, Nordstrom, Kisinbay, Restrepo, 2009). Furthermore, in some cases, the exchange-rate moves very volatile persistently then it should be minimized with additional monetary policies beyond exchange-rate intervention. In this regard, interest rate policy may be powerful to support exchange rate stability as well as price stability in order to achieve sustainable economic growth.

\subsection{The Foreign Exchange Market and Purposes of Foreign Exchange Intervention}

Volatility in foreign exchange rates can disrupt domestic economy through deteriorating imports and exports performance, decreasing cross-border investment and funding, and threaten the stability of domestic prices through changes in prices for imported or exported goods (passed-through power of exchange rate to inflation). As a result, this could affect the domestic economy and even the economies of trading partners abroad. Therefore, the monetary 
authority even with ITF should manage the exchange rate to support the achievement of domestic price stability and domestic economy by applying monetary policies such as foreign exchange intervention. While many central banks objectives are to set the optimal level of foreign-exchange that support price stability achievement as well as to mitigate exchange-rate volatility, however, others prefer to limit exchange rate volatility rather than to meet a specific target for the level of the exchange rate. Beyond on that, most central banks admit that domestic interest is still the main reason why they enter the foreign-exchange market in a sustained basis. For example as summarized in BIS publication (2006), major emerging central banks in Asia perform selling intervention to halt the continuing their currency appreciation between the end of 2001 and the end of 2004. As a consequence, global foreign exchange reserves grew by over US\$1600 billion, reflecting reserve accumulation by emerging market economies. This phenomenon shows the emerging central banks was actively enter the foreign exchange market to avoid their undesired appreciation of their currencies as it would harm their export competitiveness/ domestic economy.

On the other hand, some central banks have different views on exchange rate. They conversely prefer to stay behind from the foreign exchange intervention such as few developed countries have actively intervened within the last decade. There are some reasons behind that decision. One of them suggests foreign exchange intervention policy is not good for the economy where unbalances exist. Letting the exchange rate fluctuate freely is a sign of economic rebalancing is working. In this case, the dynamics of the exchange rate is a functioned as automatic stabilizer for the economy. This argument is elaborated in the studies by Calvo and Reinhart (2000) which concludes the foreign exchange intervention is a kind of fear of floating phenomenon. BIS (2006) summarizes reasons why developed countries no longer actively intervene foreign-exchange market. BIS suggest that the instrument is only effective if regarded as additional policy interest rate. Another reason implied that large-scale intervention can undermine the stance of monetary policy independence. The last reason is that private financial markets have enough capacity to absorb and manage shocks - so let the market determine the exchange rate.

There are many economists are interested to see the effectiveness of exchange rate intervention which conducted by central bank due to stabilize the exchange rate. However, there are also the differences about the view of exchange rate intervention affectivity to stabilize the exchange rate. Taylor (2004) examines the effectiveness of exchange rate intervention by using Markov switching model applied to dollar-mark data for the period 1985-98. In his conclusion, Taylor shows that the intervention increase the probability of stability when the rate is misaligned, and that its influence grows with the degree of misalignment. However, intervention within a small neighborhood of equilibrium will result in a greater probability of instability. Beine, Grauwe, and Grimaldi (2009) investigated the effect of sterilized intervention in a noise trading channel with two states Markov switching model. Using biweekly data, they found that interventions increase the weight of fundamentalists in the foreign exchange market 
and therefore exert stabilizing influence on the exchange rate. The fundamentalist behavior tends to stabilize the market while the presence of chartists may cause destabilization. Other study by Dominguez (1998) explored the effect of foreign exchange intervention by the G-3 central banks (US, German, and Japanese) on the behavior of exchange rates over the 19771994 period. The results indicate that intervention operations generally increase exchange rate volatility.

\subsection{Foreign Exchange Market Microstructure and Foreign Exchange Intervention}

Within microstructure approach, exchange-rate behavior is investigated. As discussed previously, the microstructure approach of exchange rate studies suggested two new channels through which sterilized intervention may be transmitted. In this regards, foreign-exchange intervention influence the expectations of foreign-exchange traders which are defined as fundamentalist and chartists. In this case, Frankel and Froot (1988) developed a model incorporate both players which is used to forecast the exchange rate expectations by them. The fundamentalist approach forecasts exchange rate expectation by the fundamentalists based upon economic fundamentals, whereas the chartist approach forecasts exchange-rate expectation by chartists based upon the past behavior of the exchange rate. Furthermore, this model is developed by Vigfusson (1996) by implementing the Markov regime-switching model, in which explains the Chartist and Fundamentalists (C\&F). He also suggests that using MA chartist model appears to do much better the AR chartist model. In this approach there are two rules in which two forecasting equations of both chartist and fundamentalist set up to estimate foreign exchange expectations. In each equation, C\&F model placed the time-varying weight.

The further research from Reitz (2002) is about the usage of C\&F model to analyze the exchange rate behavior by the market players and also investigate the impact of foreign exchange intervention by central bank to the exchange rate expectations by the traders. Reitz propose a generalization of the noise trader transmission mechanism to examine the impact of central bank intervention on exchange rates. Within a heterogeneous expectations exchange rate model intervention operations are supposed to provide support to either chartist or fundamentalist forecasts, which forces portfolio managers to adjust their foreign currency positions. He test the model by applying daily US-dollar/DEM forward rates and intervention data of the Deutsche Bundesbank and the Federal Reserve from 1979 to 1992 in the model. He finds that the performance of simple chartist trading rules was strong whenever these central banks intervened on the foreign exchange market. Instead, the fundamentalists which use the fundamentalist technique has a worse estimation results.

In Australia, the RBA's approach to foreign exchange market intervention has evolved since the float of the Australian dollar in 1983, as the Australian foreign exchange market has developed and market participants have become better equipped to manage their foreign exchange risk. Over time, foreign exchange market intervention has become much less frequent 
and more targeted towards addressing periods of market dysfunction. Obviously since 2008, the foreign exchange intervention by the RBA has been suspended.

\section{METHODOLOGY}

\subsection{The Chartist-Fundamentalist (C \& F) Model Specification}

In this part of paper, the market exchange rate of USD/IDR is built through the interaction of foreign-exchange demand-supply in domestic foreign-exchange market. The foreign-exchange supply and demand is set up by foreign-exchange market players transactions. In the foreignexchange market, the players can be categorized in two parts i.e. fundamentalist and chartist who have foreign-exchange expectations based on their own rule. Generally, chartists build their own foreign-exchange expectations using technical analysis rules to explore paste movements of exchange rate in the future. Meanwhile, fundamentalists build their exchange-rate expectations based on macroeconomic indicators such as inflation, interest rate, productivity, etc. Each of expectations are regarded as long-run equilibrium or steady state for each foreign-exchange players within their own regimes.

The fundamentalist and chartist expects that market exchange rate will converge to its long-run or steady state rate within a specific period depending on the current deviation between market exchange-rate and the respected steady state value. In this research, basic model is adopted from Maatoug, Fatnassi, Omri (2010: 30-34) and Reitz (2002: 3-7). The exchange rate is built by interactions between foreign exchange market traders which is divided into 2 groups i.e fundamentalist and chartists. Fundamentalists forecasting rules and Chartists forecasting rules can be expressed, respectively, as follow: This paper applies the markov-switching approach on exchange rate expectation by fundamentalists and chartists in Indonesia as suggested by Reitz (2002). This paper will also augment the basic model with some contemporaneous variables beside exchange-rate return and exchange-rate intervention with other variables such as NDF return and CDS. These such augmented variables are used as they may have significant impact on exchange-rate behavior.

Within this specification as also suggested by Frankel and Froot (1986: 24-38), the exchange-rate $S_{t}$ is driven by the decisions of foreign-exchange players (chartist and fundamentalist) to buy or sell foreign currency based on their expectation of future exchangerate changes and augment by a set of contemporaneous variables included in a vector $z_{t}$. Hence, the model specification is written as:

$$
s_{t}=\alpha E_{t}\left[r_{t+1}\right]+\beta z_{t}
$$


where the vector of elasticities of the contemporaneous variables $(\beta)$ and the elasticity of exchange rate expectation $(\alpha)$ should be constant overtime.

As proposed by Frankel and Froot (1986: 24-38), the market exchange rate return will be generated by the two players' exchange rate expectations or a mixture of chartist $E_{t}^{c}\left[\left[r_{t_{+1}}\right]\right]$ and fundamentalist $\mathrm{E}_{\mathrm{t}}^{\mathrm{f}}\left[\left[\mathrm{r}_{\mathrm{t}_{+1}}\right]\right]$ forecasts:

$$
\mathrm{E}_{\mathrm{t}}\left[\left[\mathrm{r}_{\mathrm{t}+1}\right]\right]=\Phi_{\mathrm{t}} \mathrm{E}_{\mathrm{t}}\left[\mathrm{r}_{\mathrm{t}+1}^{\mathrm{f}}\right]+\left(1-\Phi_{\mathrm{t}}\right) \mathrm{E}_{\mathrm{t}}\left[\mathrm{r}_{\mathrm{t}+1}^{\mathrm{c}}\right]
$$

The parameter $\Phi_{t^{\prime}}$ denoting the weight given to fundamentalist views at date $t$, this expectation is dynamically updated by the fundamentalist in a rational Bayesian manner:

$$
\Delta \Phi_{\mathrm{t}}=\delta\left(\Phi_{\mathrm{t}_{-1}}^{*}-\Phi_{\mathrm{t}-1}\right)
$$

With :

$$
\Phi_{\mathrm{t}_{-1}}^{*}=\frac{r_{t}-E_{t}^{c}\left(r_{t}\right)}{E_{t-1}^{f}\left[r_{t}\right]-E_{t-1}^{c}\left[r_{t}\right]}
$$

Where $\Phi_{t}{ }^{*}$ is estimated weight given to group of fundamentalist when expecting future exchange rate. Meanwhile, the value of $\delta$ reflects the extent to which portfolio managers enclose new information from central bank intervention using adaptive process. Since portfolio managers always maintain a positive weight for both chartist and fundamentalist forecasts, $\Delta \Phi$ has to be restricted so that $\Phi$ stays in the range between 0 and 1 reflected the portion of each group (fundamentalist and chartist) when determining exchange rate. Meanwhile, to optimize the weight assigned to fundamentalist, Lewis (1989: 79-100) assume fundamentalist forecasts exchange rate by means of a Bayesian learning process as follow:

$$
\Phi_{t}=\frac{\Phi_{t_{-1}} \cdot \Phi_{f}\left(r_{t} \mid E_{t-1}^{f}\left[r_{t}\right]\right)}{\omega_{t-1} \cdot \varphi_{f}\left(r_{t} \mid E_{t-1}^{f}\left[r_{t}\right]\right)+\omega_{t-1} \cdot \varphi_{c}\left(r_{t} \mid E_{t-1}^{c}\left[r_{t}\right]\right)}
$$

Where $\varphi_{c}\left(r_{t} \mid E_{t-1}^{c}\left[r_{t}\right]\right)$ and $\left.\varphi_{f}\left(r_{t} \mid E_{t-1}^{f}\left[r_{t}\right]\right)\right)$ is density function of foreign-exchange return $r_{t}$ of chartist and fundamentalist, respectively. With regard to fundamentalist view, the market exchange-rate is assumed to revert to long-run fundamental equilibrium $\widetilde{s_{t}}$, within a given speed $\theta$ over time depending on the current gap between current exchange-rate $s_{t}$ and long-run fundamental exchange rate, i.e.:

$$
E_{t}^{f}\left[r_{t+1}\right]=\theta\left(\widetilde{s_{t}}-s_{t}\right)
$$

Meanwhile, regarding to chartist view, the market exchange-rate is assumed to revert to long-run chartist equilibrium $\widetilde{s_{t}}$, within a given speed $\psi$ over time depending on the current gap between current exchange-rate $s_{t}$ and long-run chartist exchange rate $\widetilde{s_{t}}$, i.e.: 


$$
E_{t}^{c}\left[r_{t+1}\right]=\psi\left(\widetilde{s_{t}}-s_{t}\right)
$$

In this model, the market exchange rate is built by interactions between fundamentalist and chartists in foreign-exchange market. Each group of players believe that market exchange rate will equate to their own expectation in a specific period of time which is denoted by $\theta$ (a speed of adjustment of the market exchange-rate for fundamental rule) and $\psi$ (a speed of adjustment of the market exchange-rate forchartist rule). Meanwhile, $\widetilde{s_{t}}$ is the long-run fundamental (chartist) exchange rate which is built based on economic indicator (previous) data behaviour by fundamentalist (chartist). According to fundamentalist, foreign-exchange expectation by the exchange-rate traders can be moved as distributed symmetrically around its fundamental value $\widetilde{s_{t}}$. Although several researchers implement PPP as proxy of exchangerate fundamental value, this paper employs uncovered interest parity (UIP) as the long-run fundamental value $\widetilde{s_{t}}$. The model above explains that market exchange-rate will converge to its fundamental value $\widetilde{s_{t}}$ in the long run. A study using PPP by Takagi (1991) provides evidence there is a valid relationship between market exchange-rate and fundamental exchange rate only in the long run implying low values for $\theta$. This view is also supported by Taylor and Peel (2000) and Taylor (2001) showing that due to its nonlinear dynamics the exchange rate reverts to the PPP level, but only in the long run. Furthermore, PPP or UIP as a measure of the fundamental exchange rate $e_{t}$ seems to be suitable for the investigation of central bank intervention, because monetary authorities have used it as a target level (Dominguez and Frankel, 1993).

As defined by Maatoug, Fatnassi, Omri (2010) this study specify two states of unobserved latent variables (fundamentalist and chartists regimes) to be incorporated in the model denoted by variable $I_{t}\left(I_{t}=c\right.$ for chartist regime $I_{t}=f$ for fundamentalists one). The state of regimes is parameterized as a first order Markov process and is driven by first-order transition probabilities which expressed as follow:

$$
\begin{aligned}
& p=\operatorname{prob}\left(l_{t}=f \mid l_{t-1}=f\right) \\
& q=\operatorname{prob}\left(l_{t}=c \mid l_{t-1}=c\right)
\end{aligned}
$$

The transition probabilities between regimes (fundamentalist-chartist) are assumed to be constant over time. Fundamentalist transition probabilities $(p)$ is the probability of exchange rate expectations will remain in the fundamentalist regime, and chartist exchange-rate expectation transition probabilities $(q)$ for the chartist stay in the chartist regime which are described as follow:

$$
\begin{aligned}
& p=1-\left(1-\exp \left(\pi_{0}\right)\right)^{-1} \\
& q=1-1-\left(1-\exp \left(\kappa_{0}\right)\right)^{-1}
\end{aligned}
$$


If market exchange rate does not converge to its fundamental value in the long run, central banks will enter the foreign exchange market. The efforts of the central banks on foreign exchange markets can be called effective, if the adjustment of the current exchange rate to its long run fundamental equilibrium is accelerated.

\subsection{The Foreign Exchange Intervention/Monetary Policy Augmented Regime-Switching-C\&F Model: RS-CF-Int-NDF-CDS}

Reitz (2002) outlined exchange-rate expectation modeled using Markov switching approach both in the conditional mean and variance for both fundamentalists and chartists. Inspired by the model this paper defines the mean equation of the first regime represent the fundamentalist regime including the deviation of the exchange rate from its fundamental value $e_{t}$ describe by Uncovered Interest Parity (UIP) as outlined above. UIP is chosen because it reflects the monetary policy instrument to achieve desired domestic price as well as to support sustainable economic growth. The mean specification model for fundamentalist is defined as follow:

$$
E_{t}^{f}\left[r_{t+1}\right]=\theta\left(U I P_{t-1}-e_{t-1}\right)
$$

This paper expands the original model by augmenting Foreign Exchange Intervention (I), Non-Delivery Forward (NDF) USD/IDR, and Credit Default Swap (CDS) rate variable to see the impact of foreign exchange intervention by the central bank, NDF and CDS to foreign exchange rate expectation by the market players (fundamentalists and chartists). In introducing foreign exchange intervention/monetary policy operations into the regime-switching framework, this research defines that the dummy variable $I_{t}=1$, if the central bank intervenes (by foreign exchange intervention/monetary policy) at time $t$ and $l_{t}=0$, otherwise and rewrite the mean equations of the standard C\&F model as follow:

$$
E_{t}^{f}\left[r_{t+1}\right]=\zeta_{t}\left(U I P_{t}-e_{t-1}\right)
$$

for fundamentalist augmented rule model, where

$$
\zeta_{t}=\theta+\delta_{\theta} I_{t}+\alpha_{\theta} N D F_{t}+\omega_{\theta} C D S_{t} \text { where } \theta, \delta_{\theta}, \alpha_{\theta}, \omega_{\theta}>0
$$

This implies that the observed reversion of the exchange rate to PPP or UIP - denoted by $\zeta_{\mathrm{t}}$ - is driven by fundamentalist speculation, central bank intervention, NDF rate and CDS rate. Denoting the influence of foreign exchange intervention/monetary policy by $\delta_{\theta^{\prime}}$ NDF by $\alpha_{\theta}$ and CDS by , this research can formulate $\zeta_{t}$ as a function of a 0,1- exchange rate intervention dummy, $N D F_{t}$ and $C D S_{t}$

Meanwhile, Reitz (2002) defines the second regime's mean equation contains chartist expectation. Chartists are foreign-exchange player who believe that current exchange rate will 
move to its long-run average value measured by technical trading rules concerning previous exchange-rate behavior i.e. the moving average trading consisting of the differences between $\mathrm{ma}_{3}$ and $\mathrm{ma}_{200}$. Meaning that chartists are supposed to expect that a future exchange rate moves are predicted by the proportion $\psi$ of the positive difference between the 3 day moving average $\left(\mathrm{ma}_{3}\right)$ and 200 day moving average $\left(\mathrm{ma}_{200}\right)$ and vice versa, in this case. Hence, chartist exchange rate expectation is defined as:

$$
E_{t}^{c}\left[r_{t+1}\right]=\psi\left(m a_{200, t}-m a_{3, t}\right)
$$

The variance of $\Delta$ et, i.e. the volatility of $e_{t}$ is assumed to be constant within regimes, $h_{0 t}$ $=\sigma_{F}^{2}$ and $h_{1 \mathrm{t}}=\sigma_{c}^{2}$ thus the source of conditional heteroscedasticity is the regime switching behavior.

Generally, a central bank will conduct foreign-exchange interventions implementing a leaning against the wind-strategy to change the traders foreign-exchange expectation back to chartist long-run exchange rate average value of $m a_{200, t}$. In this type of study, subsequent changes in noise trader's positions magnify the initial impact of intervention operations, augmented by other significant variables such as NDF and CDS. Hence, the model specification can be rewritten as follows:

$$
E_{t}^{c}\left[r_{t+1}\right]=\eta_{t}\left(m a_{200, t}-m a_{3, t}\right),
$$

This implies that a given trend in the exchange rate $\left(\eta_{t}\right)$ is due to chartist speculation, central bank intervention, augmented by other variables such as NDF and CDS rate. Denoting the influence of foreign exchange intervention/monetary policy by $\delta \psi$, NDF by $\alpha_{\psi}$ and CDS by $\omega_{\psi}$ this research can formulate $\eta_{t}$ as a0,1-intervention dummy $I_{t^{\prime}} N D F_{t}$ and CDS $S_{t}$ as follows:

$$
\eta_{t}=\psi++\delta_{\psi} I_{t}+\alpha_{\psi} N D F_{t}+\omega_{\psi} C D S_{t} \text { where } \psi, \delta_{\psi}, \alpha_{\psi}, \omega_{\psi}>0
$$

Clearly, if the foreign exchange intervention of the central bank had an impact on the forecasting performance of chartists and fundamentalists, a change of coefficients represented by significant estimates of the various $\delta$, should be observed. By introducing intervention dummies, NDF rate, and CDS rate in the specification of second moment, the conditional variance becomes:

$$
h_{0 t}=\sigma_{F}^{2}+\delta_{\sigma_{F}^{2} \cdot I_{t}}+\delta_{\sigma_{F}^{2} \cdot N D F_{t}}+\delta_{\sigma_{F}^{2} \cdot C D S_{t}}
$$

for the fundamental regime, and

$$
h_{1 t}=\sigma_{c}^{2}+\delta_{\sigma_{c}^{2}} \cdot I_{t}+\delta_{\sigma_{c}^{2}} \cdot N D F_{t}+\delta_{\sigma_{c}^{2}} \cdot C D S_{t}
$$


for the chartist regime. Thus, this paper is able to re-examine the relationship between central bank intervention, NDF, CDS and exchange rate volatility.

\section{RESULT AND ANALYSIS}

\subsection{Data}

The data are daily for the sample period 2006 - 2012. All variables are in logarithms except for the interest rate variables, which are in annual terms. The foreign variable is US Federal Funds Rate. The Indonesian variables are domestic o/n interbank interest rate, the underlying consumer price index, NDF USD/IDR Rate, CDS rate, the USD/IDR spot exchange rate, and foreignexchange intervention by $\mathrm{BI}$. The microstructure of foreign exchange in Indonesia is still limited as few traders exist in foreign exchange market. Even though there are 72 foreign exchange banks in Indonesia, only about 22 to 38 banks actively trade in the foreign exchange market. However, Bank Indonesia state that the microstructure of the domestic foreign exchange market also influences the effectiveness of intervention. The net supplier of foreign exchange is still dominated by domestic state-owned banks, while foreign banks' supply or demand depends on capital inflow/outflow. The volume of transactions tends to be larger during periods of heavy portfolio inflows. Most foreign-exchange transactions are spot accompanied by swap, although forward transactions are developing. There are counter-party transaction limits, especially for smaller banks. Foreign-exchange transactions must have underlying and are limited to domestic players only (Warjiyo, 2013).

\subsection{Evidence of Exchange Rate Expectation \& Central bank's Intervention in Indonesia}

The models described above were estimated by maximum likelihood. Parameter estimates were obtained using the BFGS algorithm, and the reported t-statistics are based on heteroscedastic-consistent standard errors (White, 1982). The estimates are derived from the daily USD/IDR spot exchange rate series kindly supplied by Bloomberg. The UIP was constructed using daily O/N Interbank rate of IDR and USD. The intervention dummy series is based on intervention data kindly provided from Bank Indonesia. The foreign exchange intervention series only includes active foreign-exchange interventions made by Bank Indonesia to influence foreign exchange rates. Foreign-exchange intervention by $\mathrm{Bl}$ is reported whenever they changed their net foreign assets. The sample extends from January 2006 to June 2012. The series of the spot exchange rate, the UIP relation and the 200 day moving average are presented in upper graph, Bank Indonesia purchases and sales of Dollars against IDR can be seen as vertical graph in Figure 1. 


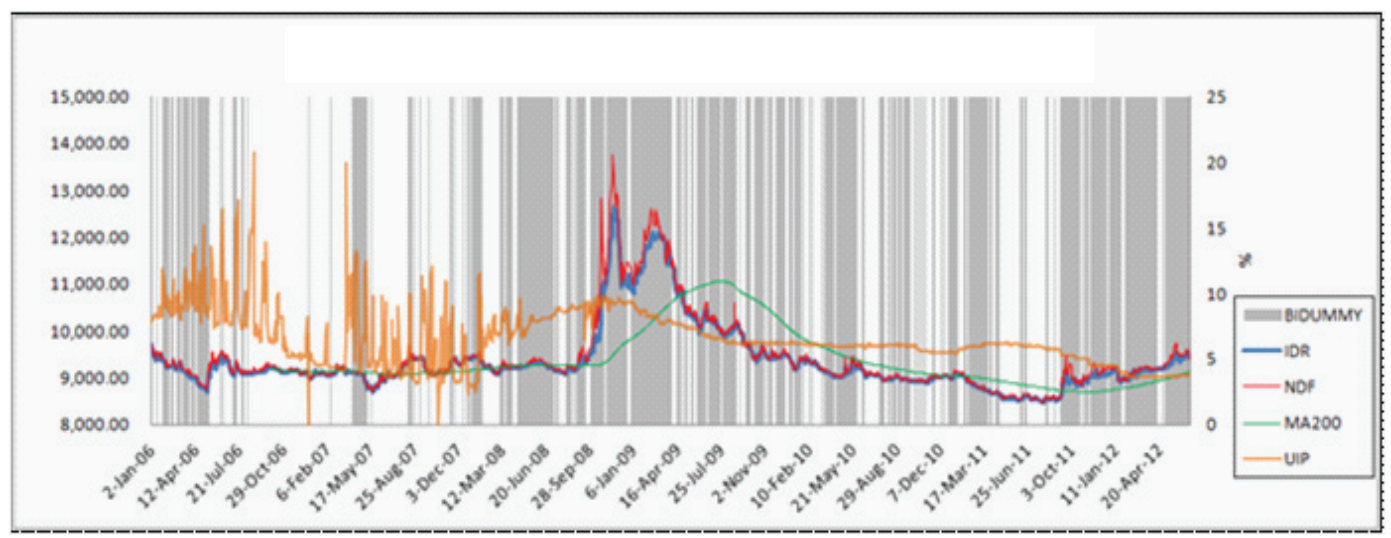

Source: author's calculation

Figure 1.

USD/IDR spot rate,UIP, MA 200 and BI FX intervention

\begin{tabular}{|c|c|c|c|c|}
\hline \multicolumn{5}{|c|}{$\begin{array}{c}\text { Table } 1 \\
\text { Estimation Result }\end{array}$} \\
\hline & RS-CF & RS-CF-Int & RS-CF-Int-NDF & RS-CF-Int-NDF-CDS \\
\hline$\theta$ & $\begin{array}{r}0,094 \\
(11,47)^{\star \star *}\end{array}$ & $\begin{array}{r}0,075 \\
(11,13)^{\star * \star}\end{array}$ & $\begin{array}{r}0,075 \\
(10,06)^{\star \star *}\end{array}$ & $\begin{array}{r}0,079 \\
(8,17)^{\star \star \star}\end{array}$ \\
\hline$\delta_{\theta}$ & & $\begin{array}{r}0,034 \\
(2,68)^{\star * \star} \\
\end{array}$ & $\begin{array}{r}0,035 \\
(2,89)^{\star * *} \\
\end{array}$ & $\begin{array}{r}0,033 \\
(2,79)^{\star * *}\end{array}$ \\
\hline$\alpha_{\theta}$ & & & $\begin{array}{l}0.051 \\
(1,50)\end{array}$ & $\begin{array}{r}0.063 \\
(1,83)^{\star *}\end{array}$ \\
\hline$\omega_{\theta}$ & & & & $\begin{array}{r}-1,43 \times 10^{-3} \\
(-0,95)\end{array}$ \\
\hline$\psi$ & $\begin{array}{r}0,045 \\
(5,65)^{\star * *} \\
\end{array}$ & $\begin{array}{r}0,049 \\
(12,60)^{\star * \star}\end{array}$ & $\begin{array}{r}0,031 \\
(4,82)^{\star \star \star} \\
\end{array}$ & $\begin{array}{r}0,023 \\
(2,90)^{\star * \star} \\
\end{array}$ \\
\hline$\delta \psi$ & & $\begin{array}{r}-0,020 \\
(-2,88)^{* * *}\end{array}$ & $\begin{array}{l}-0,012 \\
(-1,60)\end{array}$ & $\begin{array}{r}-7,96 \times 10^{-3} \\
(-0,95)\end{array}$ \\
\hline$\alpha_{\psi}$ & & & $\begin{array}{r}0,147 \\
(9,93)^{\star \star \star}\end{array}$ & $\begin{array}{r}0,119 \\
(4,37)^{\star \star *}\end{array}$ \\
\hline$\omega \psi$ & & & & $\begin{array}{r}7,86 \times 10^{-3} \\
(4,35)^{\star * *}\end{array}$ \\
\hline$\sigma_{F}^{2}$ & $\begin{array}{r}3,85 \times 10^{-5} \\
(5,22)^{* \star *}\end{array}$ & $\begin{array}{r}2,07 \times 10^{-5} \\
(4,99)^{* \star *}\end{array}$ & $\begin{array}{r}2,12 \times 10^{-5} \\
(6,18)^{\star * *}\end{array}$ & $\begin{array}{r}2,08 \times 10^{-5} \\
(4,51)^{\star * *}\end{array}$ \\
\hline$\delta_{\alpha_{F}}^{2}$ & & $\begin{array}{r}2,90 \times 10^{-5} \\
(1,66)^{*}\end{array}$ & $\begin{array}{r}2,99 \times 10^{-5} \\
(2,09)^{* *}\end{array}$ & $\begin{array}{r}2,97 \times 10^{-5} \\
(1,74)^{*}\end{array}$ \\
\hline$\sigma^{2} \mathrm{C}$ & $\begin{array}{r}2,36 \times 10^{-6} \\
(6,80)^{* * *}\end{array}$ & $\begin{array}{r}1,97 \times 10^{-6} \\
(6,77)^{\star \star \star *}\end{array}$ & $\begin{array}{r}1,60 \times 10^{-6} \\
(6,33)^{\star * *}\end{array}$ & $\begin{array}{r}1,39 \times 10^{-6} \\
(4,74)^{\star \star \star *}\end{array}$ \\
\hline$\delta_{\alpha^{2} \mathrm{C}}$ & & $\begin{array}{r}6,21 \times 10^{-7} \\
(1,17)\end{array}$ & $\begin{array}{r}8,00 \times 10^{-7} \\
(2,00)^{* *}\end{array}$ & $\begin{array}{r}7,83 \times 10^{-7} \\
(0,88)\end{array}$ \\
\hline$P$ & $\begin{array}{r}0.888 \\
(22,64)^{\star * *}\end{array}$ & $\begin{array}{r}0.890 \\
(18,67)^{\star \star \star}\end{array}$ & $\begin{array}{r}0,814 \\
(12,87)^{\star \star *}\end{array}$ & $\begin{array}{r}0,784 \\
(11,18)^{\star \star \star} \\
\end{array}$ \\
\hline Q & $\begin{array}{r}0,931 \\
(58,87)^{\star \star *}\end{array}$ & $\begin{array}{r}0,926 \\
(32,19)^{\star \star *}\end{array}$ & $\begin{array}{r}0,894 \\
(23,71)^{\star \star \star}\end{array}$ & $\begin{array}{r}0,853 \\
(18,17)^{\star \star *}\end{array}$ \\
\hline
\end{tabular}




\begin{tabular}{c|c|c|c|c}
\multicolumn{5}{c}{ Table 1 } \\
\multicolumn{1}{c|}{} & \multicolumn{5}{c}{ Estimation Result (Continued) } \\
$\overline{\mathrm{P}}$ & RS-CF & RS-CF-Int & RS-CF-Int-NDF & RS-CF-Int-NDF-CDS \\
\hline $\bar{Q}$ & 0,380 & 0,400 & 0,365 & 0,360 \\
\hline$(1-\mathrm{P})^{-1}$ & 0,620 & 0,600 & 0,635 & 0,640 \\
\hline$\left(1-\mathrm{Q}^{-1}\right.$ & 8,90 & 9,06 & 5,39 & 3,82 \\
\hline $\begin{array}{c}\text { Log- } \\
\text { Likelihood } \\
\text { LRT }\end{array}$ & 14,52 & 13,57 & 9,39 & 6,80 \\
\hline
\end{tabular}

Source: Author's Calculations

Note: The sample contains daily observations of the USD/IDR spot exchange rate from January 2006 to June 2012. See text for meaning of symbols. t-statistics in parentheses are based on heteroskedastic-consistent standard errors. The likelihood ratio test statistic is asymptotically $\chi^{2}$ (df)-distributed with df indicating the numbers of restrictions. * ${ }^{* *}$ and ${ }^{* * *}$ denotes significance at the $90 \%, 95 \%$ and $99 \%$ level, respectively.

Table 1 contains the estimates of the RS-CF, the RS-CF-INT, RS-CF-INT-NDF and RS-CFINT-NDF-CDS models. As regards the smoothed transition probabilities, the all models differ slightly at best. $p$ and $q$ range above 0.78 thereby indicating high persistence of regimes. The unconditional probability of the fundamentalist regimes $\bar{p}=\frac{1-\mathrm{q}}{2-\mathrm{p}-\mathrm{q}}$ is lower than the one assigned to chartist regimes for all respected models. This is also reflected in the expected duration of fundamentalist regime. In the RS-CF model (a), the (first) fundamentalist regimes $(1-p)^{-1}$ is expected to last up to 8.9 trading days where as the (second) chartist regimes $(1-q)^{-1}$ have a longer duration of at least 14.5 trading days. Meanwhile, the fundamentalist rule USD/IDR expectation share is $\bar{p}$ about $38 \%$ smaller than the chartist rule USD/IDR expectation $\bar{q}(62 \%)$ in performing USD/IDR market rate. Significant estimates of variances point to regime dependent heteroscedasticity capturing periods of high and low volatility: the variance in the second regimes $\sigma_{c}^{2}$ in these conditional regimes is lower than the variance in the first regimes $\sigma_{F}^{2}$. The estimates of chartist and fundamentalist coefficients $\psi$ and $\theta$, are statistically significant and of the correct sign despite showing very low values meaning the market exchange rate will converge to their own steady-state value in the long run. These findings are supported by other study by Takagi (1991). He provides evidence there is a valid relationship between market exchange rate and fundamental exchange rate only in the long run implying low values for $\theta$. 


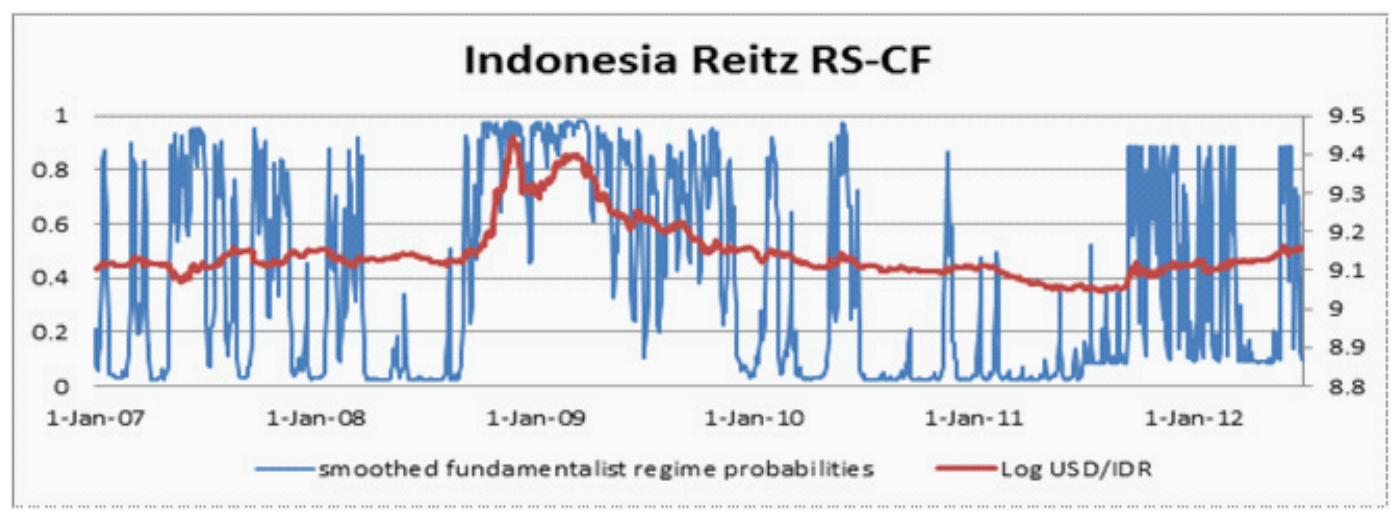

Figure 2. Smoothed Probabilities "basic model"

In the RS-CF-INT model (b), the (first) fundamentalist regimes are expected to last up (1 $p)^{-1}$ to 9 trading days where as the (second) chartist regimes $(1-q)^{-1}$ have a longer duration of at least 13.5 trading days. Even it is better that model (a) because of $\mathrm{BI}$ exchange rate intervention, the fundamentalist rule USD/IDR expectation share $\bar{p}$ is about $40 \%$ still smaller than the chartist rule USD/IDR expectation $\bar{q}(60 \%)$ in performing USD/IDR market rate. Significant estimates of variances point to regime dependent heteroscedasticity capturing periods of high and low volatility: the variance in the second regimes $\sigma_{c}^{2}$ in these conditional regimes is still lower than the variance in the first regimes $\sigma_{F}^{2}$ even though for chartist it gets smaller variance. The estimates of chartist and fundamentalist coefficients $\psi$ and $\theta$, are also statistically significant and of the correct sign.

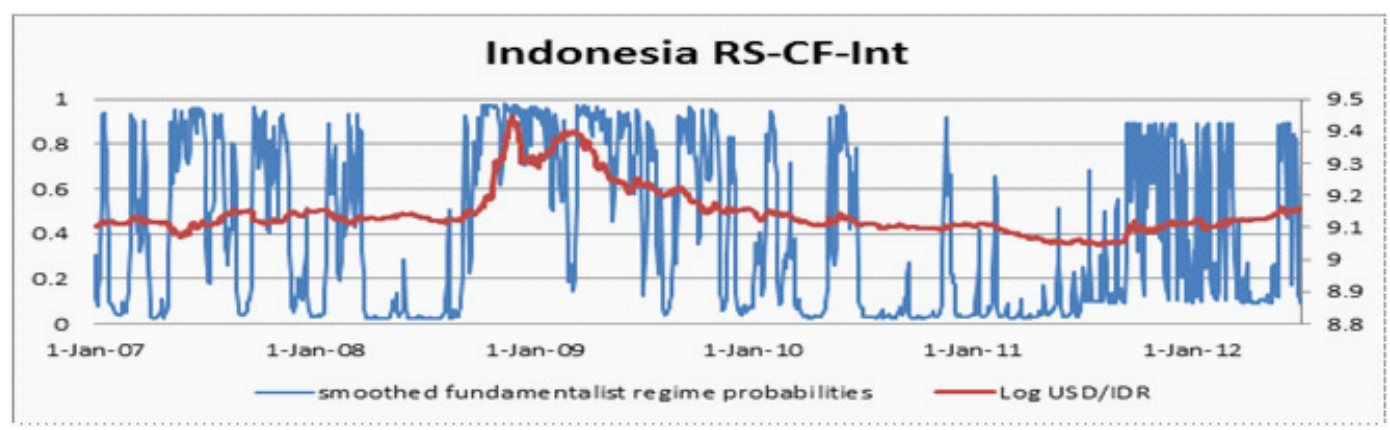

Figure 3. Smoothed Probabilities "basic model augmented with FX Intervention"

In the RS-CF-INT-NDF model (c), the (first) fundamentalist regimes are expected to last up $(1-p)^{-1}$ to 5.4 trading days where as the (second) chartist regimes $(1-q)^{-1}$ have a longer duration of at least 9.4 trading days. Because of $\mathrm{Bl}$ exchange rate intervention and NDF rate variable, the fundamentalist rule USD/IDR expectation share $\bar{p}$ decreases to about $37 \%$ which is 
even smaller than the chartist rule USD/IDR expectation $\bar{q}(63 \%)$ in performing USD/IDR market rate. Significant estimates of variances point to regime dependent heteroscedasticity capturing periods of high and low volatility: the variance in the second regimes $\sigma_{c}^{2}$ in these conditional regimes is still lower than the variance in the first regimes $\sigma_{F}^{2}$ even though for chartist it gets smaller variance. The estimates of chartist and fundamentalist coefficients $\psi$ and $\theta$, are also statistically significant and of the correct sign.

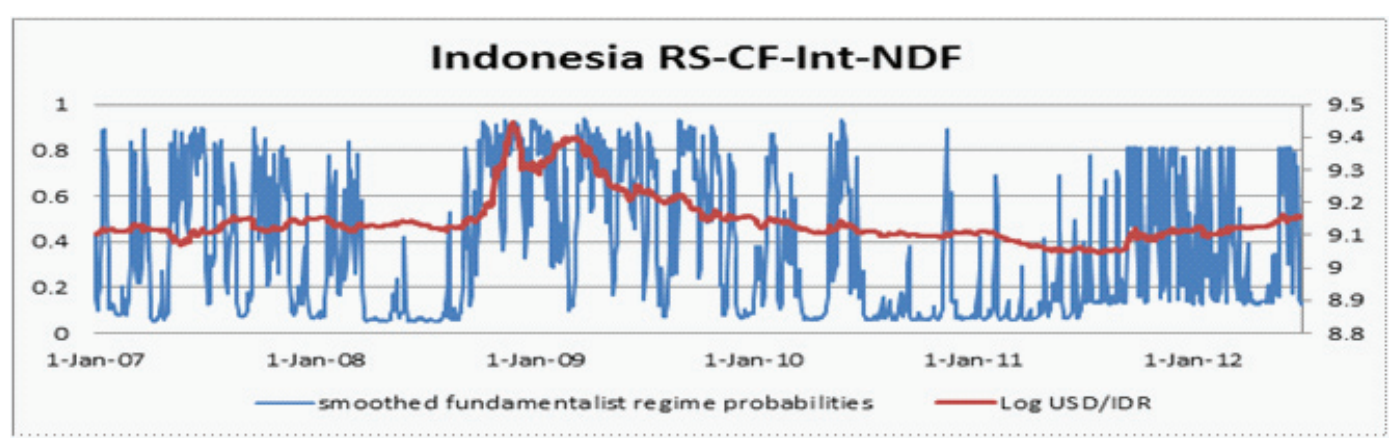

Figure 4. Smoothed Probabilities "basic model augmented with FX Intervention \& NDF"

In the RS-CF-INT-NDF-CDS model (d), the regime switching is getting faster than those in previous models meaning of increasing exchange rate uncertainty, the (first) fundamentalist regimes are expected to last up $(1-p)^{-1}$ to 3.8 trading days where as the (second) chartist regimes $(1-q)^{-1}$ have a longer duration of at least 6.8 trading days. Because of $B$ l exchange rate intervention, augmented with NDF rate, and CDS $1 \mathrm{mth}$ variable, the fundamentalist rule USD/IDR expectation share $\bar{p}$ decreases to about $36 \%$ which is even smaller than the chartist rule USD/IDR expectation $\bar{q}(64 \%)$ in performing USD/IDR market rate. Significant estimates of variances point to regime dependent heteroscedasticity capturing periods of high and low volatility: the variance in the second regimes $\sigma_{c}^{2}$ in these conditional regimes is still lower than the variance in the first regimes $\sigma_{F}^{2}$ even though for chartist it gets smaller variance. The estimates of chartist and fundamentalist coefficients $\psi$ and $\theta$, are also statistically significant and of the correct sign. 


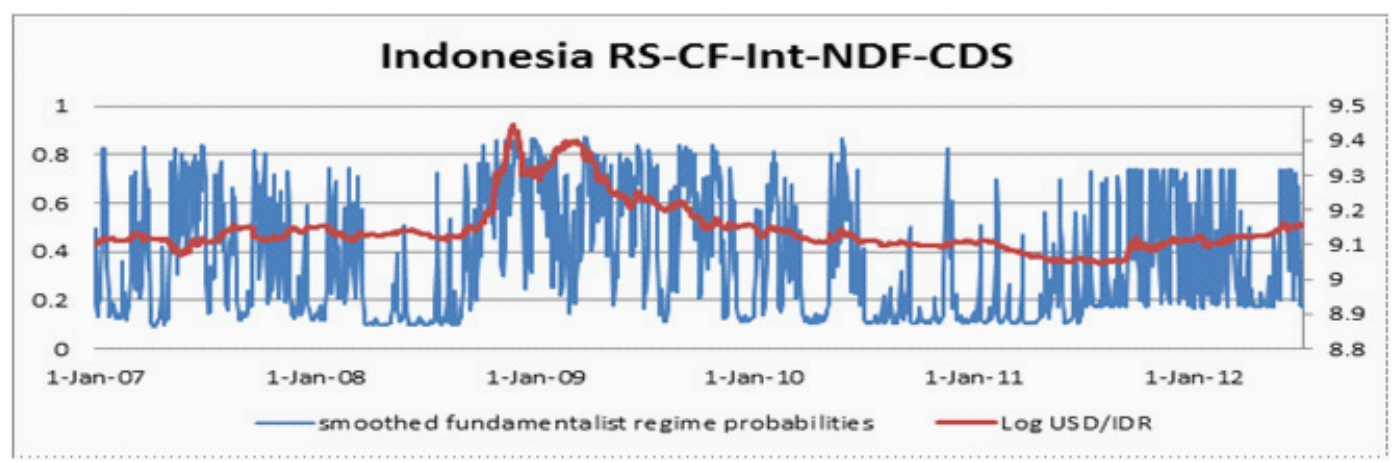

Figure 5. Smoothed Probabilities model augmented with FX Intervention \& NDF \& CDS"

Figure Smoothed Probabilities of USD/IDR in the basic model (a) no intervention, no NDF \&CDS, (b) augmented with BI intervention, (c) augmented with BI intervention \& NDF, (d) augmented with $\mathrm{BI}$ intervention, NDF, and CDS.

However, the most important results from these Markov switching procedures are significant parameter estimates of chartist and fundamentalist forecasting techniques within the heterogeneous expectations framework. As has been outlined in the theoretical section of the paper, central bank interventions are supposed to affect exchange rates by influencing chartist and fundamentalist forecasting success. Because the standard RS-CF model is nested in the more general RS-CF-INT-NDF-CDS model, the hypothesis can be examined by the values of the log-likelihood functions, the likelihood ratio test (LRT) statistic and the estimates of the various $\delta_{s^{\prime}} \alpha_{s^{\prime}} \omega_{s^{\prime}}$ in table 1 .

As the LRT statistic suggests, the consideration of intervention dummies, NDF, and CDS, explain a significant improvement in the log-likelihood function. Hence, the hypothesis that exchange rate expectations are not affected by central bank interventions, NDF, and CDS has to be rejected. Particularly, the results of parameter estimates give rise to the conclusion that foreign exchange activities of Bank Indonesia, NDF and CDS, could have supported fundamentalist and chartists rules. The dummy exchange-rate intervention coefficient $\delta_{\theta}$ of the central bank is significant and reports a significant increase of $\zeta_{t}$ whenever $I_{t}=1$. In the case of addition of new variable 'NDF' and 'CDS', respectively the coefficient $\alpha_{\theta}$ of the central bank is still significant, while $\omega_{\theta}$ is insignificant. However, totally the effect, reports a significance increase of $\zeta_{t^{\prime}}$ meaning that speed of adjustment to long-run/fundamental value is increasing when fundamentalists dominated the market and central banks intervene.

When looking at the link between central bank intervention, within chartist exchange rate expectations model, the (b) model recognizes insignificant decreasing change of $\eta_{t}$ as $\delta_{\psi}$ show negative value though insignificant. This implies that the adjustment of the exchange rate to its long run equilibrium has been decelerated in periods when chartists dominated the market 
and central banks intervene. In the case of addition of new variable 'NDF' and 'CDS' to the chartist model as shown in (d) model, the coefficient $\alpha_{\psi}$ and $\omega_{\psi}$ are surprisingly significant and reports a significance increase of $\eta_{t^{\prime}}$ meaning that speed of adjustment to its long-run value is increasing because of NDF and CDS (even though $\delta_{\psi}$ - decrease the speed of adjustment to its long run equilibrium in one hand when chartists dominated the foreign exchange market).

Regarding to volatility in relation with central bank's FX Intervention, this research finds that this is confirmed by the finding that the FX intervention dummy (especially in fundamentalist regime) in the model RS_CF_INT, identified periods in which the volatility is a bit increase except in chartist regime which is not significant, as shown in Table 1. It has also same conclusion when using model (d), while model (c) reports contradiction. However, the result should be very careful before quickly concluding that exchange rate volatility increase in fundamental regime is due to intervention operations. Rising uncertainty of global financial condition which may ignite sudden and massive capital flows, disorderly markets, speculative transactions behaviour, may hamper central bank intervention policy. This is confirmed in a study by Baillie and Osterberg (1997a) that find evidence that foreign-exchange interventions by US, German, and Japanese central banks have tended to increase foreign-exchange volatility in the USD/JPY forward market when JPY/USD is under pressure. This is also supported by findings in a study by Giner and Mendoza (2005) which argues that foreign-exchange intervention appears to be effective in short time or the effectiveness will be short-lived. He also finds that the more frequently exchange-rate intervention applied by the central bank, the effectiveness would be smaller. In the case of Indonesia, the central bank enters the foreign exchange market almost every day, this might confirm why the volatility is conversely increased. Furthermore, excessive exchange-rate fluctuations might be found as another factor that halts Bank Indonesia effort to reach the effectiveness of foreign exchange market in driving exchange rate to its long-run fundamental or in achieving price stability condition. This phenomenon, making central bank intervention remains an ambiguous policy tool in influencing exchange rates.

\section{CONCLUDING REMARKS}

In this research, the effect of central bank intervention within a heterogeneous expectation exchange-rate model, is investigated. The results are supporting both chartists and fundamentalist regimes. It is shown that the two regimes are persistent. The estimates of chartist and fundamentalist coefficients $\psi$ and $\theta$, are statistically significant and of the correct sign despite showing very low values meaning the market exchange rate will converge to their own steady-state value in the long run. In the period investigated, chartist dominates in the exchange rate determination. As the LRT statistic suggest, the consideration of foreign-exchange intervention dummies explain a significant improvement in the log-likelihood function. Hence, the hypothesis that exchange rate expectations are not affected by central bank interventions has been rejected. Particularly, the result of parameter estimates give rise to the conclusion that 
foreign exchange activities of BI could have supported fundamentalist (UIP) \& chartist (Moving Average) trading rules but in opposite direction. The dummy BI FX interventions coefficient in the fundamentalist period $\delta_{\theta}$ is positive whereas in the chartist period $\delta \psi$ is negative; but only the coefficient of fundamentalist is highly significant in the complete model (d).

When looking at the link between BI FX intervention within both fundamentalist/chartist exchange rate expectations, this study recognizes very significant change of $\zeta_{t}$ and $\eta_{t}$ but in opposite direction. This implies that the adjustment of the exchange rate to its long run (fundamental) equilibrium 'UIP' has been accelerated in the periods when fundamentalists dominated the market and central bank intervenes as it improve the performance of expectations based on fundamentals, especially when central banks try to correct current exchange rate misalignments. On the other hand, the adjustment of the exchange rate to its long run (fundamental/chartists equilibrium) has been decelerated in the periods when chartists dominated the market and central bank intervenes.

In the case of Indonesia, it is shown that the predictive power of fundamentalist forecasting techniques approximated by the deviation of the current exchange rate from the UIP level, were enhanced whenever the Bank Indonesia intervened on the foreign exchange market. There is evidence that within this framework, central bank operations on foreign exchange market has been called effective, as the adjustment of the exchange rate to its long run (fundamental) equilibrium is accelerated when fundamentalists dominated the market and central bank intervenes, not when chartists dominated the market. It means that the impact of central bank intervention on foreign exchange rates is only effective when assessed by means fundamentalist regime approaches. In this regards, Bank Indonesia's foreign-exchange intervention has been able to drive the USD/IDR to long-run/fundamental 'UIP' as assumed in fundamentalist rule.

With regard to exchange-rate volatility, however, Bank Indonesia efforts to exert a stabilizing effect of foreign exchange interventions, the result still does not show what Bank Indonesia wants as the variance shows increasing value. Several factors such as external shocks and disorderly foreign exchange market which beyond Bank Indonesia control, may play significant role behind this findings.

\section{POLICY IMPLICATION}

In this research, the effect of central bank intervention within a heterogeneous expectation exchange rate model is investigated. The results are supporting both chartists and fundamentalist regimes. In the period investigated, chartist dominates in the exchange rate determination. While BI foreign exchange intervention can push the market rate to its long-run fundamental equilibrium, however, Bank Indonesia's effort to exert a stabilizing effect of foreign exchange interventions, the result does not show a success. 
As a policy implication, the central bank should pay attention more to the foreign-exchange market player, especially the fundamentalist and chartist as they have a significant role in determining market exchange rate. The central bank should drive exchange rate expectation to the fundamentalist's rule as it is relevant with monetary objective in achieving targeted inflation. Furthermore, foreign-exchange intervention is proven effective when exchange rate expectation is dominated by fundamentalist. As consequence, the central bank should implement optimal monetary policy with appropriate strategy especially in determining optimal interest rate and exchange rate intervention as well as implement governance aspects of monetary policy.

For a small open economy like Indonesia, exchange rate movement does not always reflect fundamental value. Increasing USD/IDR exchange rate volatility often occurs as a result of rising uncertainty of global economic condition which ignites sudden massive capital flows, irrational behavior of market players, the microstructure conditions of the market, and offshore market influence.

As a policy implication, relying solely on Bank Indonesia's interest rate policy to achieve the inflation target and maintain stability is not always sufficient. The central bank's strategy is to include exchange rate policy in the monetary and macro-prudential policy in order to achieve its goal more effectively. 


\section{REFERENCES}

Ahrens, R., \& Reitz, S. (2003). Heterogeneous Expectations in the Foreign Exchange Market Evidence from the Daily Dollar/DM Exchange Rate. CFS Working Paper. No 2003/11. German.

Almekinders, G. J., \& Sylvester, C. W. (1996). A Friction Model of Daily Bundesbank and Federal Reserve Intervention. Journal of Banking and Finance 20, 1365-1380.

Baillie, R., \& Osterberg, W. (1997a). Central Bank Intervention and Risk in the Forward Market. Journal of International Economics, Vol. 43, 483- 497.

Baillie, R., \& Osterberg, W. (1997b). Why Do Central Banks Intervene?. Journal of International Money and Finance Vol 16, 909-919.

Beine, M., Grauwe, P. D., Grimaldi,M.(2009). The Impact of FX Central Bank Intervention in a Noise Trading Framework. Journal of Banking \& Finance,33(7), 1187-1195.

Brunetti C, Mariano R. S., Scotti, C. (2007). Markov Switching GARCH Models of Currency Turmoil in Shoutheast Asia. Emerging Markets Reiview, Elsevier. 9(2):104-128.

Calvo, G. A., \& Reinhart, C. M. (2000). Fear of Floating . Quarterly Journal Economics 117 , 379-408.

Clarida, R. H., Sarno, L., Taylor, M. P., Valente, G. (2001). The Out-of-Sample Success of Term Structure Models as Exchange Rate Predictors: A Step Beyond, Mimeo.

Dewachter, H. (1996). Charts as Signals in Markov Switching World. Applied Economics Letters, Taylor and Francis Journals, 3 (6), 405-407.

Dewachter, H. (2001). Can Markov Switching Models Replicate Chartist Profits in the Foreign Exchange Market?. Journal of International Money and Finance, Vol.20,25-41.

Dominguez, K. M. (1998). Central Bank Intervention and Exchange Rate Volatility. USA: Journal of International Money and Finance, 17.

Dominguez, K. M., \& Frankel, J. A. (1993). Does Foreign-Exchange Intervention Matter? the Portfolio Effect. The American Economic Review, 83 (5), 1356-1369.

Engel, C. H. (1994). Can the Markov Switching Model Forecast Exchange Rates?. Journal of International Economics, Vol. 36, 151 - 165.

Engel, C. H., \& Hamilton, J. (1990). Long Swings in the Dollar: Are They in the Data and Do Markets Know It? American Economic Review Vol. 80, 689 - 713. 
Frankel, J. A., \& Froot, K. A. (1990). Chartist, Fundamentalists, and Trading in the Foreign Exchange Market. The American Economic Review, Vol. 80, No. 2 Papers and Proceedings of the Hundred and Second Annual Meeting of the American Economic Association, 181185.

Frankel, J. A., \& Froot, K. A. (1989). Chartists, Fundamentalists, and Trading in the Foreign Exchange Market. American Economic Review Papers and Proceedings, Vol.80,181-185.

Frankel, J. A., \& Froot, K. A. (1988). Forward Discount Bias: Is It an Exchange Risk Premium? Barkeley, California: Working Paper 8874 Department of Economics.

Frankel, J. A., \& Froot, K. A. (1986). Understanding the US Dollar in the Eighties: The Expectations of Chartists and Fundamentalists. The Economic Record, 24 - 38.

Frankel, J. A., Schmukler, S. L., \& Serven, L. (2004). Global Transmission of Interest Rates: Monetary Independence and Currency Regime. Journal of International Money and Finance Volume 23, Issue 5, 701-733.

Hamilton, J. D. (1989). A New Approach to the Economic Analysis of Nonstationary Time Series and the Business Cycle. Econometrica .

Hung, J. (1997). Intervention Strategies and Exchange Rate Volatility: A Noise Trading Perspective. Journal of International Money and Finance, Vol. 16, 779 - 793.

Ito, T., \&Yabu, T. (2007). What Prompts Japan to Intervence in the Forex Market? A New Approach to A Reaction Function. Journal of International Money and Finance Volume 26, Issue 2, 193-212.

Lewis, K. (1989). Can Learning Affect Exchange-Rate Behavior? - The Case of the Dollar in the Early 1980's. Journal of Monetary Economics, 79 - 100.

Maatoug, A. B., Fatnassi, I., Omri, A. (2010). Central Bank Intervention Within a ChartistFundamental Exchange Rate Model: Evidence from the RBA Case. Journal of Economic and Financial Modelling. 1(1):30-34.

Neely, C., \& Weller, P. (2001). Technical Analysis and Central Bank Intervention . Journal of International Money and Finance, Vol. 20, 949 - 970.

Reitz, S. (2002). Central Bank Intervention and Exchange Rate Expectations - Evidence from the Daily DM/US-Dollar Exchange Rate. Discussion Paper 17/02. Economic Research Centre of the Deutsche Bundesbank.

Reitz, S., \& Taylor, M. P. (2008). The Coordination Channel of Foreign Exchange Intervention: A Nonlinear Microstructural Analysis. European Economic Review. 52 (1), 55 - 76.

Röthig, A., Semmler, W., Flaschel, P. (2005). Corporate Currency Hedging and Currency Crises. Publications of Darmstadt Technical University, Institute of Economics (VWL) 27194, 
Darmstadt Technical University, Department of Business Administration, Economics and Law, Institute of Economics (VWL).

Stone, M., Roger, S., Shimizu, S., Nordstrom, A., Kisinbay, T., Restrepo, J. (2009). The Role of the Exchange Rate in Inflation-Targeting Emerging Economies. Washington: IMF Occasional Paper 267 (Washington: International Monetary Fund).

Takagi, S. (1991). Exchange Rate Expectations, A Survey of Survey Studies. IMF Staff Papers, Vol. 38 (1).

Taylor, J. B. (2001). The Role of the Exchange Rate in Monetary-Policy Rules. American Economic Review. 91 (2), 263-267.

Taylor, M. P. (2004). Is Official Exchange Rate Intervention Effective? . Economica, 71. The London School of Economics and Political Science, 1-11.

Taylor, M. P. (2000). Nonlinear Adjustment, Long Run Equilibrium and Exchange Rate Fundamentals . Journal of International Money and Finance, 19, 33-53.

Taylor, M. P. (2005). Official Foreign Exchange Intervention as A Coordinating Signal in the Dollar-Yen Market. Pacific Economic Review, 10 (1), 73-82.

Taylor, M. P. (1995). The Economics of Exchange Rates . Journal of Economic Literature

Vigfusson, R. (1996). Switching Between Chartists and Fundamentalists: A Markov RegimeSwitching Approach. Working Paper 96-1. Bank of Canada.

Warjiyo, P. 2013. Indonesia: Stabilizing the Exchange rate along Its Fundamental. BIS Paper no. 73. Bank for Internatioanal Settlements.

Westerhoff, F. (2003). Speculative Markets and the Effectiveness of Price Limits. Journal of Economic Dynamics and Control, 28, 493-508.

White, H. (1982). Maximum Likelihood Estimation of Misspecified Models . Econometrica, Vol. $50,1-25$.

Wieland, C., \& Westerhoff, F. (2005). Exchange Rate Dynamics, Central Bank Interventionand Chaos Control Methods. Journal of Economics Behavior and Organization, 58, 117-132. 